\title{
Correspondence
}

\section{Sotalol, hypokalaemia, syncope, and torsade de pointes}

Sir,

The report on sotalol, hypokalaemia, syncope, and torsade de pointes by McKibbin et al $(1984$; 51:15762) contains certain errors of fact and interpretation.

It cites "several reports . . . that . . . [sotalol] may be arrhythmogenic." The first reference, ${ }^{1}$ however, was a study of patients with arrhythmias treated by sotalol, which was successful in 35 of 38 patients. There are no data suggesting that sotalol was arrhythmogenic. The other citations were of particular extreme clinical conditions-that is, iatrogenic or deliberate overdosages. For example, the authors state that; "Elonen and associates reported six cases of severe poisoning . . ." whereas the accurate statement is that six patients unsuccessfully attempted suicide by using sotalol as a poison (the lowest dose being $2.4 \mathrm{~g}$ ).

We have examined the worldwide incidence of any case of syncope or torsade de pointes under any circumstance associated with the use of sotalol or Sotazide in the past year. Of the 859000 prescriptions for sotalol and the 343000 for Sotazide, representing $80 \%$ and $98 \%$ of the sotalol and Sotazide markets respectively, the incidence of syncope or torsade de pointes with sotalol and Sotazide was $0.002 \%$ (25 incidents/1 202000 prescriptions). Of these, five were suicide attempts, three were unrelated to sotalol treatment, and two were electrophysiologically induced. Of the remaining 15 patients, six were over 65 years of age and receiving other medications, two had severe diarrhoea immediately before the event, two had been on a drinking spree, and the final two had been advised to increase their sotalol maintenance dose. These latter patients are clearly an unusual subset but similar to those reported by Mckibbin et al . They were largely elderly patients (nine of 13 over 65 years of age), were simultaneously receiving medications which by themselves could cause torsade de pointes, were receiving relatively large doses of sotalol-some for long periods of time-and, by and large, should not have been treated with sotalol or Sotazide in the manner in which they were.

The most common predisposing factor to torsade de pointes is severe bradycardia. ${ }^{2}$ Thus, because all beta blockers reduce heart rate, any might cause syn- cope or torsade de pointes. This has particular relevance since the beta blockers, propranolol, metoprolol, and pindolol, which do not have class III activity, caused a 7-16\% incidence of arrhythmia aggravation or induction. ${ }^{3}$ Moreover, the package insert for timolol approved by the Food and Drug Administration in the USA lists as side effects: incidence of bradycardia (9.1\%), arrhythmia (1.1\%), and syncope $(0.6 \%)$. It seems clear that the major conclusion of the authors that other beta blockers do not confer any arrhythmogenic risk is incorrect.

The report of McKibbin et al is important in describing an unusual collection of cases. Nevertheless, the importance of hypokalaemia, concurrent drugs, and the non-specific nature of the purported reaction limit its extrapolation to a general recommendation for either sotalol or its combination with hydrochlorothiazide.

When prescribed according to the manufacturer's recommendations, particularly with regard to electrolyte imbalance, sotalol and Sotazide have proved to be as safe and effective as any other beta blocker or beta blocker combination for the treatment of hypertension.

Michael J Antonaccio, Jan N Lessem, Lester F Soyka, Bristol-Myers Company, Pharmaceutical Research and Development Division, 2404 Pennsylvania Avenue

Evansville, Indiana 47721 USA.

\section{References}

1 Simon A, Berman E. Long-term sotalol therapy in patients with arrhythmias. $f$ Clin Pharmacol 1979; 19: 547-56.

2 Fontaine G, Frank R, Grosgogeat Y. Torsades de pointes: Definition and management. Mod Concepts Cardiovasc Dis 1982; 51: 103-8.

3 Velebit V, Podrid P, Lown B, Cohen BH, Graboys TB. 
Aggravation and provocation of ventricular arrhythmias by antiarrhythmic drugs. Circulation 1982; 65: 886-94.

This letter was shown to the authors, McKibbin and colleagues, who reply as follows:

Sir,

Our citing of Simon and Berman ${ }^{1}$ in a context that sotalol "may be arrhythmogenic" was a typographical error for which we apologise. We contend that our paper contains no other "errors of fact and interpretation."

The statement by the manufacturers, based on a "worldwide survey", that "the incidence of syncope or torsade de pointes with sotalol and Sotazide was $0.002 \%$ (25 incidents/1 202000 prescriptions)" does not impress us, and we question their sources of information. We also remind them that side effects of many drugs have been missed for years until a first observation is made or a careful investigation is undertaken. The detection of the deleterious effects of practolol and of thalidomide exemplify this.

Because sotalol has a class III antiarrhythmic action surely it is readily understandable that it will also have arrhythmogenic effects in some instances? Although we emphasised that the presence of hypokalaemia or the concurrent use of other drugs which prolong the QT interval were highly important factors in the development of polymorphous ventricular tachycardia and syncope in most of our patients taking sotalol, Kuck et al have now reported the case of a 40 year old woman taking sotalol $320 \mathrm{mg}$ daily who developed torsade de pointes but in whom no electrolyte disturbances were detected. ${ }^{2}$ After our paper was accepted for publication, we encountered two more patients, both hypokalaemic, who developed syncope during sotalol treatment.

It is not a "major conclusion" of ours that "other beta blockers do not confer any arrhythmogenic risk." We did not discuss that aspect. Our principal conclusions relate to the recognition that sotalol has unique antiarrhythmic, and therefore also arrhythmogenic, properties. We suggest that sotalol is superior to other beta receptor blocking agents in the treatment of conditions in which the class III effect is relevant. We assert that the combination of sotalol with a thiazide diuretic should be avoided in the long term treatment of a condition such as hypertension, in which hypokalaemia commonly ensues.

Our message is a simple one, and we consider that it is in the interest of many patients that the manufacturers of sotalol accept it.

Joseph K McKibbin, Wendy A Pocock, John B Barlow, Israel WP Obel, Department of Cardiology, University of the Witwatersrand, Johannesburg,

South Africa.

\section{References}

1 Simon A, Berman E. Long-term sotalol therapy in patients with arrhythmias. I Clin Pharmacol 1979; 19: 547-56.

2 Kuck KH, Kunze KP, Roewer N, Bleifeld W. Sotalolinduced torsade de pointes. Am Heart $\mathcal{F}$ 1984; 107: 179 80.

\section{Ketanserin treatment in essential hypertension}

Sir,

Fagard et al's paper (1984; 51: 149-56) on ketanserin treatment in mildly hypertensive patients includes some haemorrheological aspects which might be noteworthy. The authors found a fall in pulmonary and systemic arterial resistance during treatment which they attribute exclusively to vasodilatation. Peripheral resistance, however, is composed of two components: vascular tone and the viscous hindrance of blood flow (for example, blood viscosity). ${ }^{1}$ Blood viscosity is increased in essential hypertension ${ }^{1}$ and can be decreased by ketanserin ${ }^{2}$ and other alpha antagonists. ${ }^{1}$ This might be-a contributory factor in the changes observed by Fagard et al. In fact a closer look at their results seems to confirm this. Haemo- globin concentrations decrease and plasma volume is thought to increase with ketanserin, both of which would tend to lower blood viscosity ${ }^{3}$ and partly explain the findings.
E Ernst,
A Matrai,
Haemorrheological Research Laboratory,
University Clinic,
Ziemssenstrasse 1 ,
8000 München 2,
West Germany. 